\title{
Governance of Carbon Emissions of Electric Power Industry in China
}

\author{
Qi Wei, Shuxin Yue, Manman Tian \\ School of Economic and Manangement, Lanzhou University of Technology Lanzhou, Gansu Province, China \\ weiq@lut.cn, 464861667@qq.com
}

\begin{abstract}
In the face of increasingly stringent environmental control system and environmental capacity of limited resources, the power industry needs to seek effective environmental management tools to solve environmental constraints for future development. According to current situation of pollutant emission of the electric power industry, firstly, this article analyzes the pollution emission control measures of Chinese electric power industry. Secondly, we analyzed the carbon trading theory and practice at home and abroad, and illustrate the necessity of the power industry in our country to establish carbon trading mechanism. At the end of the paper constructed the carbon emissions trading mechanism of the electric power industry in China.
\end{abstract}

Index Terms - Electric power industry, Carbon emissions, Carbon trading.

\section{Introduction}

The power industry is the basic industry of national economy and public utilities, the proportion of primary energy conversion into electricity to a certain extent reflects a country's level of economic development and degree of environment and resources protection. The electric power industry is not only the quality of clean energy of the creator, but also a large energy consumption and pollution emitters, and thus became the key areas of the nation's implementation of energy conservation and emissions reduction. According to the State Power Information Network reported that from the current development speed and power demand forecasting, power generation capacity will reach 900 million to 1 billion kilowatts in 2020. According to the current emission levels, thermal power emissions of sulfur dioxide and fuel dust, nitrogen oxides will reach 21 million tons, 5 million tons, 10 million tons. Therefore, it is necessary to explore new development model, to go for Chinese national conditions to save resources, protect the environment and good economic benefit of development.

Emission trading, that originated from some American economists academic theory early in 1960s (Crocker, 1966; Dales, 1968), has been practiced and now evolved into an important environmental economic policy and an important approach to reducing pollution (David, 1997; UEPA, 1991; Reuters, 2007) in many countries and is also a part of the global cooperative scheme in greenhouse gas reduction (Stewart, 2007; Risa, 2008). During the 1980s, approximations to tradable permit schemes were implemented in the United States. The experience gained from emissions trading for sulfur dioxide $\left(\mathrm{SO}_{2}\right)$ and oxides of nitrogen $\left(\mathrm{NO}_{\mathrm{X}}\right)$ offers a useful body of information and data to draw on to design a GHG emissions trading system. The concept of tradable emission permits was popularized by Dales (1968) in the context of water pollution. Montgomery (1972) provided a rigorous theoretical treatment. Particularly thorough treatments of design issues have been provided by Tietenberg $(1980,1985,1993)$ and by Hahn and co-authors (Hahn, 1988, 1989; Hahn and Noll, 1982, 1990; Hahn and Hester, 1988). This literature has identified a number of potential advantages of emission trading programs compared to command-andcontrol allocation of emission targets and environmental taxation. A number of studies have reviewed the $\mathrm{SO}_{2}$ trading experience to gain insights into GHG trading (Ellerman et al. 2003; Tietenberg, 2003). One of the objectives of these systems is to encourage firms to adopt advanced abatement technologies. Extensive literature has investigated the convenience of a permits system to reach this objective (Montero, 2002; Requite and Unold, 2003, see Jaffe et al., 2003 for a survey).

\section{Pollution Emission Control Measures of Chinese Electric Power Industry}

In China, thermal power and the heating coal accounts for $51 \%$ of the national coal production, producing about $70 \%$ of the country ash, $40 \%$ of the total of industrial water is used for thermal power, fuel dust accounted for $33 \%$ of industrial emissions, sulfur dioxide emissions accounted for $56 \%$ of the industrial emissions. Therefore, electric power plays a key role in the work of resources and environment in China.

\section{A. Legal administrative regulation of electric power industry pollution}

Energy Conservation Law (revised 2008), Renewable Energy Law (2005), Cleaner Production Promotion Law (2002), Environmental Protection Law (1989), Atmospheric Pollution Prevention Law (2000), Atmospheric Pollution Law (2000) have made the relevant regulations in pollution control and prevention of electric power industry. To achieve the goal of energy conservation and emissions reduction of the electric power industry, the state council issued the "twelfth five-year" plan for energy conservation and emissions reduction requirements, thermal power industry cut by $16 \%$ in sulfur dioxide and 29\% in nitrogen oxides.

In summary, we can see that China has introduced a large number of policies and regulations for electric power industry pollution. This article describes the legal administrative regulation of electric power industry pollution from the following six aspects. 


\section{1) Application of technology to reduce emissions}

On Environment and Development Commission (2002) No.26 in Sulfur Dioxide Emissions From Coal-fired Pollution Control Technology Policy, prescribed that burning sulfur content coal is greater than or equal to $2 \%$ of the unit or the large capacity units ( $\geq 200 \mathrm{mw}$ ) the construction of power plant boiler flue gas desulfurization facilities should give priority to a wet limestone gypsum method and the desulfurization rate should guarantee the above $90 \%$, and so on. In the face of growing environmental pressures, China clean coal power generation technology and nuclear power technology is not yet fully mastered. The healthy development of the industry needs the government proper management and control. The main way is to develop and implement industrial policy. And reasonable fiscal and taxation policy can regulate, guide and adjust the economic behaviour of market entity, also can make it develop towards the direction that improve the whole social benefit to achieve the macro-control intent of government and development strategic objectives.

\section{2) Renewable energy quota system}

National Development and Reform Commission adopted a quota system at the time of approval of power projects. Renewable energy quota system refers to the legal form of renewable energy be mandatory proportion of total generating capacity, that is means that when a power generation companies to apply for new power generation capacity, they must build a certain percentage of renewable energy generation capacity. It's that the state encourages renewable energy power generation of compulsory measures.

\section{3) Shutting down small thermal power units}

To speed up the elimination of outdated small thermal power units is an important way that the electric power industry to implement the scientific development view and achieve sustainable development. The State Council Approved National Development and Reform Commission and Energy Office Notice On Accelerating The Shutting Down Small Thermal Power Units And Several Opinions (National Development and Reform Commission [2007]NO.2)clearly put forward the "11th five-year plan" to shut down the goal of 50 million mw thermal power unit. Until 2011, under the common efforts of the relevant departments, local governments and the electric power enterprise, the whole country had closed small units 76.825 million kilowatts and excess $53.6 \%$ complete closure tasks. They played an important role for the realization of the "11th five-year plan" national energy conservation and emissions reduction targets have

\section{4) The three simultaneity policy}

Environmental Protection Law (1989) stipulated in article 26 that pollution prevention facilities must be the principal part of construction project engineering "designed, constructed and put into use at the same time". The original electric power industry ministry promulgated Electricity Power Industry of environmental protection Management Measures (1996) put forward the implementation of the" three simultaneity" system. "At the same time designed, constructed and put into use" policy is controlled by the prior to prevent environmental pollution. For all possible damage to the environment construction, rebuilding and expansion of the project, and have bigger prevention pollution to electric power industry.

\section{5) Deadline for pollution control policy}

The goal of deadline for pollution control policy is through government coercion and set a deadline for the enterprises and institutions that have the serious pollution, and have the completion of environmental protection responsibility to bear. Deadline governance is to control pollution enterprises in a short period of time. This policy has a legal basis, Water Pollution Prevention Law, Air Pollution Prevention Law and other relevant provisions of the law, if the enterprises and institutions fails to complete the task by the deadline, in addition to the charge standard discharge in accordance with the provisions of the state, we also can according to the harm caused by the consequences shall be fined, or closure, shut down. For the specified finite source of pollution, the relevant government departments can focus efforts to carry out supervision and examination, and the policy of the executive power is strong. Deficiencies in, the decision deadline of governance is also exercised by the local government departments and it can not completely out of the relevant stakeholders of the enterprises and institutions, if this decided to exercise the power to the environmental protection department, can have a higher mandatory and deterrence.

\section{B. Economic regulation of electric power industry pollution in China \\ 1) The sewage charge system}

Sewage charge is paid by the polluters to centralized treat or governance pollutants. The sources of pollution charge is not national finance income or polluters economic penalties, but polluters pay for pollution control of operating costs. Sewage charge is an important economic means of environmental protection. At present, our country mainly uses sewage charge on sulfur dioxide emissions control means that all emissions of sulfur dioxide enterprise, institution and selfemployed collecting the sewage charge. In 2007 the State Council issued the Work of A Comprehensive Energy Reduction Program that improve the sewage fee collection standards for sewage units, the sulfur dioxide emission fees from 0.63 yuan per kilogram to three years up to 1.26 yuan per kilogram.

\section{2) Price Policy}

The government made clear the coal-fired power generation enterprises expected return through benchmarking electricity price policy, prompted by investing in lower coal consumption of unit to reduce the production cost profit. Through the self-provided power plant of self-provided power plant price policy to curb the construction of high coal consumption and high pollution of small units, prompting existing small unit shutting down. Through the renewable energy price subsidies to enhance the benefits of renewable energy power generation and encourage clean power generation. By establishing the reasonable price system, give full play to the price leverage, and change the behaviour of electric power producers, so as to realize the pursuit of the 
harmony of economic interests and energy-saving and emissions reduction targets.

\section{Carbon Trading theory and Practice at Home and Abroad}

Emissions rights trading are the environmental regulatory authorities to make the total emission caps, then according to the upper limit emissions quotas issued. The emission quotas can be traded in the market, and emissions trading provide incentives to reduce the cost of emission control.

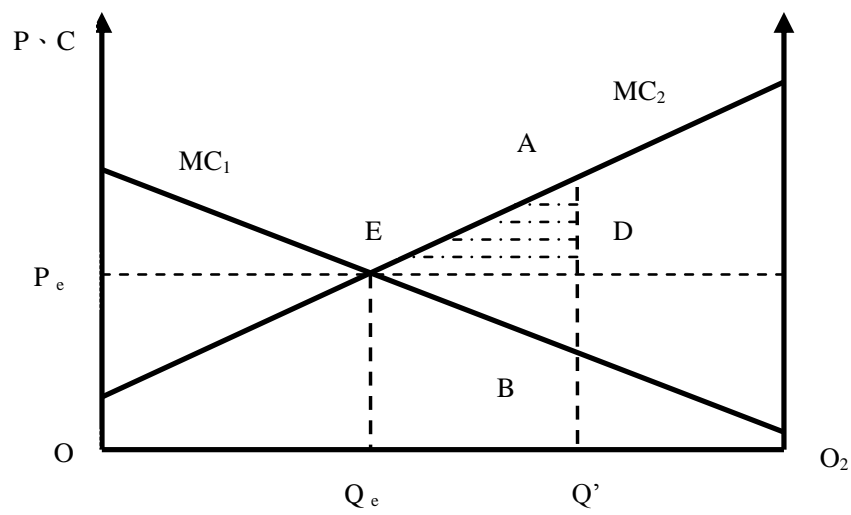

Fig. 1 The relationship between the emissions of pollution and cost of pollution control

Figure 1 shows the basic idea of emissions rights trading, the horizontal axis shows the emissions of pollution, the vertical axis represents the cost of the pollution treatment or emissions trading price. The total length of the horizontal axis is $\mathrm{O}_{1} \mathrm{O}_{2}$ of total emissions government allowed. The horizontal axis from left to right for the enterprise 1 emissions of pollution, from right to left emissions of pollution for the enterprise2. $\mathrm{MC}_{1}$ and $\mathrm{MC}_{2}$ respectively is enterprises1 and enterprises 2 of the marginal cost of pollution control, and $\mathrm{MC}_{1}$ is less than $\mathrm{MC}_{2} \cdot \mathrm{O}_{1} \mathrm{O}_{2}$ is the total emissions of the government allowed. $\mathrm{O}_{1} \mathrm{Q}^{\prime}$ is the enterprise1 the initial allocation of emission, and the corresponding standard sewage treatment cost for $\mathrm{O}_{2} \mathrm{Q}^{\prime} \mathrm{B}$. $\mathrm{O}_{2} \mathrm{Q}^{\prime}$ is the enterprise2 the initial allocation of emission, and the corresponding standard sewage treatment cost for $\mathrm{O}_{1} \mathrm{Q}^{\prime} \mathrm{A}$. So the emission trading before the total social cost of pollution control is added to $\mathrm{O}_{1} \mathrm{O}_{2} \mathrm{E}$ and triangle $\mathrm{ABE}$ area. Because of the existence of differences in the cost of pollution control, low cost of pollution control of enterprise1 through emissions trading market to sell high pollution control costs of enterprise 2 emissions of $\mathrm{Q}_{\mathrm{e}} \mathrm{Q}_{\mathrm{c}}$ capacity after two enterprises reached a trade balance short period at the point $Q_{e}$. Enterprise 2 by trading emission rights obtained $\mathrm{Q}_{\mathrm{e}} \mathrm{Q}$ ' share of emissions permits, and enterprise 1 through the trading access to the $\mathrm{Q}_{\mathrm{e}} \mathrm{Q}^{\prime}$ unit corresponding reduction of income. After a transaction is concluded, the total discharge of two enterprises pollutant is $\mathrm{O}_{1} \mathrm{O}_{2}$, but the total social cost of pollution control is reduced to triangular ADE. Then the total social cost of pollution control changes to $\mathrm{O}_{1} \mathrm{O}_{2} \mathrm{E}$ and triangular $\mathrm{BDE}$ area together, and improve the environmental capacity resource allocation efficiency.
Accompanied by the Clean Air Act (1977), the United States for the first time make emission rights trading that is the Acid Rain Program used in practice, and has been a huge success. On the one hand, sulfur dioxide emissions have slashed. In 2010, America's total emissions are 8.95 million tons, and that number is half of the 1980 emissions. On the other hand, forming a huge emissions trading market, in 2009 America sulfur dioxide emission trading conducted a total of 2716 pen, the market value of $\$ 1.1$ billion. In addition to the United States, the European Union in order to achieve the promise of the Kyoto protocol, since January 1,2005 implementation of carbon dioxide emissions trading system, and determine its trading system step by step. In April 2010, Asia's first carbon trading system - the cap of Tokyo trading system, officially launched. This is the first Japanese regional cap and trade system and the world's first city cap carbon dioxide emissions trading scheme, which aimed at the large office building, factory mandatory, involved in 1400 places, including 1100 commercial facilities and 300 factories, accounting for $20 \%$ of total emissions Tokyo. The plan to become the first Asian allows emissions quota trading cap trading system. The experiences of other countries that the complete trading system, emissions trading mechanism relative to other traditional governance policies of pollution can more effectively to control pollution, and gradually realize the emission reduction target.

\section{The Construction of Carbon Emissions Trading Mechanism of the Electric Power Industry in China}

Chinese carbon emissions trading mechanism of the electric power industry as shown in figure 2 , the specific steps are as following:

\section{A. The total emissions control}

Generation performance standard is the unit time generator or power company/power plant per watt of electricity generated by the number of some pollutants, and to reflect the strength of this kind of pollutants discharge of the unit power. Based on GPS to $\mathrm{CO}_{2}$ emission quotas are allocated to electric power industry, the first job is to determine the distribution of target the GPS baseline values of the future power plant, and then according to the power plant capacity to determine the power plant in the future allocation of emissions quota.

\section{B. The initial emission rights allocation system}

At the beginning of the establishing carbon emissions trading market in China, in order to avoid the start of the initial emission rights allocation to have much impact, and reduce the blocking some interest groups, contribute to emissions trading mechanism to implement as soon as possible and the completion of the trading market, we can adopts the principle of grandfather clause of the European Union that is adopted to allocate permits free allocation primarily way. After the market development to a certain stage, can adopt the method of combining the distribution of paid and unpaid by the government through the macroeconomic regulation and control timely adjust paid 
allocation proportion. Finally, the distribution of the form is given priority to with the auction model, and to establish a fair and efficient market system of carbon emission rights allocation.

\section{Emission permit system}

Application of emission behaviour of emissions permits is entity approved by the administrative department of proof, and relevant laws and regulations to confirm its related rights. That is the government regulates emissions trading and a powerful tool to control greenhouse gas emissions. Usually need to go through three steps: First, through the establishment of related law permits (in the form of emissions permits).Second, the emission entity shall apply, and by the competent department to examine its compliance with legal qualification, conditions and procedures. Third, the audit decision issued by the competent department under a certain procedure permits to emit, and is responsible for emissions permits the use of regulation. Therefore, emission permit include apply for permits to emit, certified and issuance of permits to emit by the three steps.

\section{Emissions and transaction registration system}

The establishment of a national registration system and registration system has a fundamental role to define and protect the emission reduction targets and promote emissions trading. First, to establish a national registration system, involved in the transaction parties shall establish an account in the system of the environmental protection department within a specified, and all emission data and transaction activities must register the account. The registration system through the standardization of the database on corporate emissions data and permits issued holding, transfer, acquisition, cancellation and recovery of data input statistics.

\section{E. Monitoring and verification system}

The greenhouse gas emissions is different from general commodity, which is a kind of intangible goods, and emissions data is provided by the discharge of entities, in order to prevent greenhouse gas emissions appeared in the process of providing false emissions data problems to cause unfair responsibility. So you need to set up independent of emitters and independent third party management department, and by a third party to inspect the emissions data validation and monitoring, to ensure the accuracy of the emissions data.

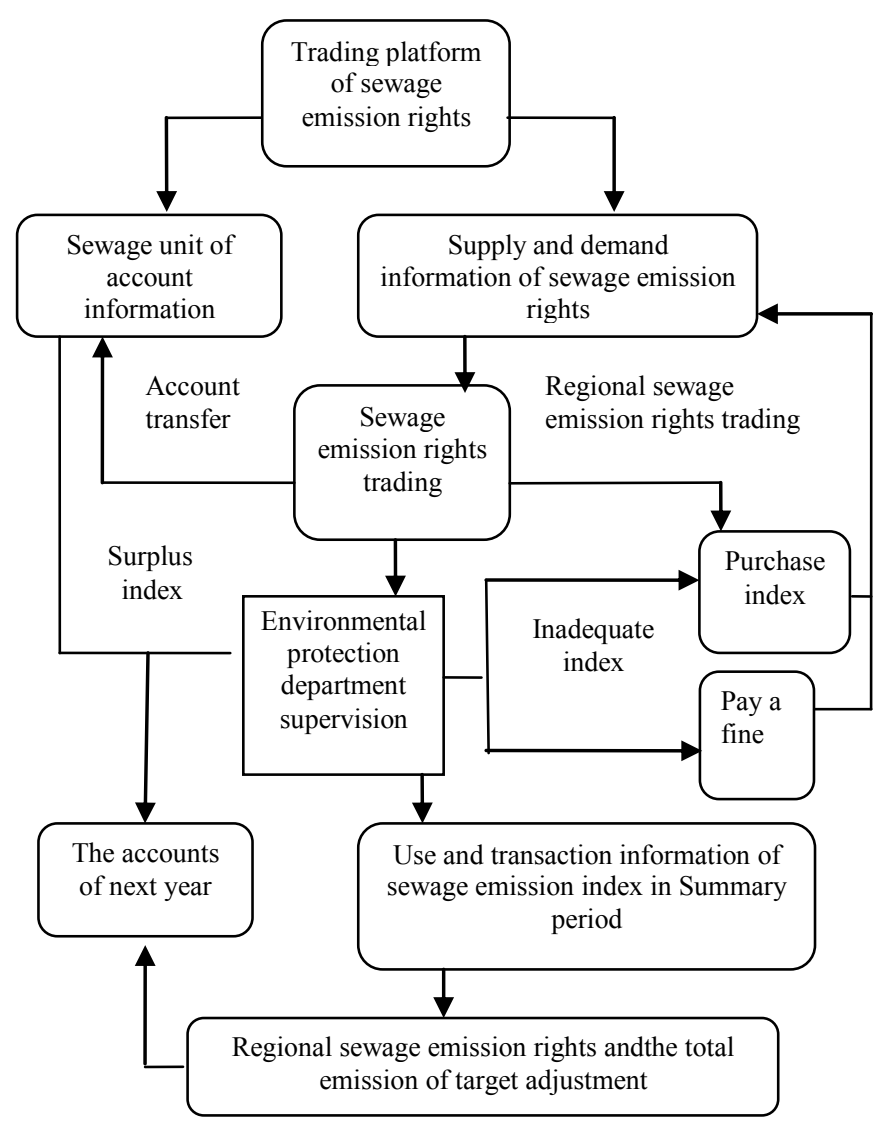

Fig. 2 Carbon trading system of the electric power industry in our country

\section{References}

[1] Shumao Zhang, "A Research on the Dilemma in China's Emission Trading System and, Relevant Countermeasures," International Journal of Business and Management, Vol. 5, no. 6, pp. 129-132,June 2010

[2] Ming Zhang, Xiao Liu, Wenwen Wang, Min Zhou, "Decomposition analysis of $\mathrm{CO} 2$ emissions from electricity generation in China," Energy Policy, Vol. 52, no. 6, pp. 159-165, March 2013

[3] Andrew Van Horn ,Edward Remedios, "A Comparison of Three Cap-andTrade Market Designs and Incentives for New Technologies to Reduce Greenhouse Gases," The Electricity Journal, Vol. 21, no. 2,pp. 51-62, March 2008

[4] Adam Millard-Ball, "The trouble with voluntary emissions trading: Uncertainty and adverse selection in sectoral crediting programs," Journal of Environmental Economics and Management, Vol. 65, no. 6, pp. 40-55, March 2013

[5] G.Chen, " Life cycle carbon emission flow analysis for electricity supply system: A case study of China," Energy Policy, Vol. 61, no. 10,pp. 12761284, October 2013

[6] Richard Schmalensee, Paul L. Joskow, A. Denny Ellerman, Juan Pablo Montero, Elizabeth M. Bailey, "An Interim Evaluation of Sulfur Dioxide Emissions Trading," The Journal of Economic Perspectives, Vol. 12, No. 3, pp. 53-68, August 1998

[7] Richard C.M. Yam, W.H. Leung, "Emissions trading in Hong Kong and the Pearl River Delta region-A modeling approach to trade decisions in Hong Kong's electricity industry," environmental science \& policy, Vol. 31, no. 4,pp. 1-12, April 2013 